\title{
Practicing Leadership-As-Practice in Content and Manner
}

\author{
A Manuscript Submitted
}

By

Joseph A. Raelin

Northeastern University

j.raelin@,neu.edu

Stephen Kempster

Lancaster University

Howard Youngs

Auckland University of Technology

Brigid Carroll

The University of Auckland

Brad Jackson

Griffith University

For Consideration To:

Leadership

All Rights Reserved 


\title{
Practicing Leadership-As-Practice in Content and Manner
}

\begin{abstract}
A collective and collaborative response to an article appearing in Leadership's "Leading Questions" department is prepared by a team subscribing to the Leadership-as-Practice (L-A-P) approach. The focus is to represent the manner in which L-A-P operates as a leadership theory and in its communal practice orientation. Among the themes addressed are L-A-P's theory development, its contribution in comparison to critical leadership theory, its approach to power, and its practicality. Emerging issues in L-A-P theory and application are also reviewed.
\end{abstract}

\section{Background and Rationale [Joe Raelin]}

Those of us however connected to the leadership-as-practice (L-A-P) movement undoubtedly took notice of Dr. Margaret Collinson's "Leading Questions" article in Leadership (2017). She raises many important criticisms in regard to our so-named "movement," which stimulates the need for critical reflexivity. For those unfamiliar with the L-A-P approach, we see leadership not as residing in the traits and behaviors of individuals (such as leaders and followers) but as an agency emanating from an emerging collection of practices. So when social and material-discursive processes and activities begin to re-orient the flow of practice towards new meanings and directions, we say that leadership is taking place.

As regards the "Leading Questions" tract, speaking just for myself, I was surprised and also saddened by the personal attributional nature of the paper. Although the polemical stance of the article might call for an individual response producing a conventional point-counterpoint discourse, I preferred to use this space and opportunity to demonstrate the difference between the expected institutionalized leader debate format and a novel dialogic format prescribed under the leadership-as-practice banner.

Consequently, I was granted the opportunity by the editor to see if I could recruit some adherents to come together and collectively respond to Margaret's critique. Four scholars came forward to offer their reflections on specific themes highlighted in the article. Besides preparing our own sections, we spent time sharing thoughts and feelings with one another on skype and via email. We traded papers and provided feedback to one another. We granted that our voices could be and should be distinct. Just as in the instance of the book, Leadership as Practice: Theory and Application, and as Steve Kempster will note below in his articulation of any theory's stages of development, we acknowledge our contention. We recognize that some of us are apologists for this stream of research. But we are also trying to display some reflexivity upon our own practice, in which we are attempting to practice what we preach and perhaps change the trajectory of conventional discourse in academic publication. In the end we just hope that our article will prompt further conversation and application of the theory and practice of leadership-as-practice, and on that account, we thank Margaret for initiating the opportunity. 
First, Professor Steve Kempster, Professor of Leadership Learning and Development at Lancaster University Management School, addresses the question of how to refer to such frameworks as leadership-as-practice. Rather than debate its location as a "movement," he prefers to consider its stage of development as an emerging leadership concept/construct.

\section{Stages of Development in Leadership Research [Steve Kempster]}

The contention about a movement is not the issue I wish to explore here. Rather I wish to examine the development of L-A-P as a concept or construct that seems most salient in relation to this article. I am sympathetic to the arguments outlined by Margaret Collinson. Indeed, her article is helpful in the context of concept/construct development. There should be attention, argument, and contestation. The history of leadership studies is too often dominated by the proliferation of various theories competing for attention as the next new idea to redirect leadership thinking. Some of these theories become fashions and dominate the scene without due attention and critique. In that context L-A-P is situated and warrants examination. Within leadership studies we seem to be most susceptible to the emergence of such offerings with little regard and value placed to systematic building of theory. In a sense leadership studies so often appears to celebrate the variety of ideas rather than assimilate them towards consensus and agreement. L-A-P should not be yet another one of these. And in that respect, I agree with the purpose of Margaret's article to trigger examination.

I suggest here that L-A-P, along with other research communities exploring and developing theories and constructs of leadership, would be well-served to embrace Reichers and Schneider's (1990) three-stage framework for the evolution of constructs. Hunt (1999) used this framework to offer a historic perspective in affirming the influence of charismatic and transformational research on the rejuvenation of the leadership field. L-A-P is not at this stage of influence. It may never be. But what it needs to do is heed the progression of concept/construct development through the three stages offered by Reichers and Schneider. If L-A-P progresses firmly into stage 3, then perhaps the body of work may then have become significant. If in that journey scholars have gathered around the emerging understanding and opportunities that L-A-P generates then perhaps a movement occurred. But that's not for now.

I first want to outline the three stages of Reichers and Schneider's framework. Then I shall explore the antecedent influences shaping the emergence of L-A-P and briefly offer a review of L-A-P work and suggest that L-A-P is firmly within stage one. I conclude with comments on the opportunity of L-A-P to embrace researchers and research from a range of orientations, perhaps a necessity if L-A-P is to progress to Stage 3 as an accepted construct informing leadership studies research.

Reichers and Schneider (1990: 5-6) define the three stages as follows:

Stage 1: Concept introduction and elaboration - Characterised by attempts to legitimize a new or borrowed concept, it seeks to engage readership with regard to concept definition and the importance of the concept. In this stage articles seek to elaborate on early definitions, methods, and insights.

Stage 2: Evaluation and augmentation. The first critical reviews of the concept appear to address faulty conceptualization, inadequate operationalization, and equivocal empirical results. "In response to and in tandem with these critiques, articles appear that attempt to overcome some of the major criticisms" (p. 6). 
Stage 3: Consolidation and accommodation. Controversies wane, review articles summarise what is known and not known, and the concept becomes utilised in a range of related (and unrelated) research.

Reichers and Schneider suggest that progression through the three stages is not necessarily chronological. Margaret's critique reflects Stage 2 but that does not imply that L-A-P has moved into Stage 2. It seems strikingly clear to me that L-A-P is in Stage 1.

The antecedents of L-A-P reflect borrowed concepts on the understanding and delineation of practice. The orientation towards practice aligns with debates in leadership studies problematizing the leaderfollower ontological assumption. This is reflected by scholars on both sides of the Atlantic (see, for example, Drath et al., 2008 and Kelly, 2014). The notion of moving away from an essentialist ontology to a processual, contextual, and practice ontology for leadership seems well-founded.

In tandem with such debates are various articles outlining the notion of L-A-P (see for example Carroll et al., 2008; Raelin, 2011). The edited collection of L-A-P (Raelin, 2016) is an appropriate step in seeking to elaborate on the introduction of concepts and outline the challenges for the concept to be developed. For example, in chapter 12 (Kempster, Parry and Jackson, 2016), the authors explored a range of research challenges that need to be overcome for the L-A-P concept to be developed - not least the need for creative approaches to understand and elaborate on the manifestations of L-A-P. There is at present a dearth of empirical work on L-A-P (Kempster and Gregory, 2016). As such we know so very little about L-A-P to be able to compare conceptualizations across contexts. L-A-P is a long way from evaluation and augmentation. The criticisms that Margaret has offered are helpful as a catalyst for clarification and elaboration of L-A-P.

The key issue going forward is how L-A-P research is to evolve. The co-ordination of research and the engagement of researchers from a range of research traditions and orientations should be embraced. For example, critical leadership research has much to contribute. L-A-P fundamentally is a concept that is centered upon structure-agency interaction. How power becomes manifest and used within contextual practice in this interaction would generate illuminating research. I see no constraint from the development of a community of colleagues from a range of traditions (positivist, constructionist, critical, realist) as long as the research, by necessity, embraces a contextual appreciation that draws on antecedent influences and emergent outcomes. It would be antithetical for L-A-P, for example, to pursue a nomological network with assumptions of law-like regularity. However, L-A-P researchers should not shy away from seeking to connect conceptual understanding of structural and agency dynamics by which L-A-P becomes manifest. The L-A-P agenda should embrace helping managers understand how L-A-P develops in their working environments and how they may be central agents in the on-going production of the same.

Picking up from Steve, Dr. Howard Youngs, who is Senior Lecturer and Director of International Development \& Relations in the School of Education, Auckland University of Technology, sees L-A-P as a potential critical contributor to leadership studies. He shows that L-A-P can be positioned across the individual, post-heroic, and critical fields of leadership. 


\section{The Potential of L-A-P as a Critical Contribution to Leadership Studies [Howard Youngs]}

The approach I take here is both a personal narrative towards a developing practice perspective and also a response to Margaret Collinson's timely questions. I say timely as this is to be expected as an aspect of early construct development as discussed above by Steve Kempster. Early construct development can also be evident in its uptake beyond those positioned (in this case Joe Raelin by Margaret Collinson) as enthusiasts. There is more going on beyond his work and that of the authors in his edited book in relation to processual and practice approaches to leadership. So, in a way, there is (a) movement but this cannot progress without initial critique, contestation, and augmentation. First of all though, how have I come to engage with L-A-P?

I have always been situated in the field of education, first as a secondary school teacher, head of department, and deputy principal. My transition into the theory, practice, postgraduate teaching, and research of educational leadership was in parallel to my doctoral research into distributed leadership. Understandably, a practice lens has been at the forefront of my academic endeavors. Education (and in particular educational leadership), like other public services, has undergone its own managerial colonization (Thrupp \& Wilmott, 2003) through neoliberal policy reforms and New Public Management (NPM). The subsequent increase of accountability measures, the narrowing of what outcomes can be measured, albeit with cut-backs of resources, has led to work intensification. Economic capital is positioned with more power over education through State intervention and market pressures, rather than through social and cultural forces (Thomson, 2005; Youngs, 2017a). NPM came to the forefront of reforms at the same time the leadership field engaged with distributed, shared and post-heroic conceptualizations of leadership. In education there was now too much work for a small group of leaders, so the popularization of distributed leadership in education was not a surprise due to the wider distribution of this work (Youngs, 2009). Policy and the market can have a power over how both the education and leadership fields evolve. Dichotomization (Collinson D, 2014) (such as individual and collective) and minimal engagement with power (Youngs, 2009) can lead to over-simplified understandings of theory and how practice unfolds. This is perhaps why Gronn (2011) has shifted from distributed perspectives of leadership to hybrid configurations, as neither individual nor collective approaches can alone be adequate for social theorizing in and beyond organizations (Archer, 1995). This brings into question our own meta-structures we may adhere to in the leadership field, namely the implied (and perhaps real for some) separation of individual/heroic and distributed/post-heroic positions. In the same spirit in which Margaret questions L-A-P, we also need to stand back and ask whether these two positions (with Critical Leadership Studies looking on) are helpful for knowledge production, especially when there is a multi-billion dollar leadership industry that will seek to protect its own product of leadership. The reason for making this point is that it is sometimes helpful to go outside what has become the norm to look back in. For me, this is what L-A-P potentially can offer. I say potentially, because it does need to be inherently critical and clearly illustrate an ontology that contrasts with other models in the leadership field.

In addition to Joe Raelin's and others' writings of L-A-P, a parallel and separate approach has been emerging in education. For example, Kemmis et al. (2014) have for some years been developing a practice theory approach informed by the practice theorist Theodore Schatzki and others (2001). Of particular interest is Wilkinson's and Kemmis' (2015) questioning of why leading is assumed to be the practice that can be placed above other forms of practice and be responsible for them. Unless we question the power we attribute to the concept and nomenclature of leadership, then we may not be aware of the reification it can be afforded. Starting ontologically with practice as it emerges, rather than leaders and followers first, may open up new understanding. I am not arguing here for an anti- 
leadership approach. L-A-P does offer, as long as it brings clarity to an emerging practice-based and critically informed ontology, some means to address the issues of dichotomization and over-reification of status evident in individual and distributed forms.

I also wonder if an approach to understanding practice labelled as leadership has been in front of us all of the time. For example, in my recent review of distributed and collaborative leadership studies in higher education (Youngs, 2017b), understanding practice was a theme across recommendations for research and organizational development. What is perhaps missing are enough theoretical connections to practice theory and social theory, and subsequent methodologies of research across the leadership field. This echoes Alvesson's and Spicer's (2014) call for a greater emphasis on processual studies and Crevani's (2017) recent argument for an ontology that focuses on direction forming. There does appear to be some (re)direction going on through L-A-P and other movements towards processual and practicebased approaches. What I found interesting when I located Margaret's article was that sitting below it on the journal home page was Crevani's (2017) article as well as four others that emphasized a practice approach to understanding leadership. Two of these were located in indigenous contexts, which is another area where a practice approach devoid of Western constructs of leadership may help bring critical contributions to the leadership field.

Finally, I connect back to my roots, and that of practitioner first. My practice at times may be leading, theorizing, researching, teaching or in this case, writing; at other times it will be all of these plus more. This starts to get to the heart of being human, where credence is given to the socio-cultural ahead of economics. This may not fit snuggly into rational and positivist perspectives of leadership. Nor is it helpful to separate individual and distributed forms, as these co-exist, albeit in the interplay of power relations, neo-liberalism, and the market. Yes, a critical position must inherently underpin L-A-P and yes, there is some movement beyond those to whom Margaret referred. My hope is that L-A-P will help bring another layer of understanding across the leadership field, incorporating individual, post-heroic, and critical positions, rather than be positioned within one of them. That in itself may be deemed as critical as it questions existing structures and the power that upholds them. However, I will leave any further exploration of power and L-A-P to Brigid Carroll in the following section. Finally, we ourselves need to take care that L-A-P does not become popularized beyond conceptual development and critique and for that I thank Margaret for her contribution as we (in a loose sense) endeavor to work alongside others for the benefit of the field.

We turn next to Professor Brigid Carroll, Associate Professor in the University of Auckland Business School and one of the originators of the practice perspective in leadership. Brigid will primarily address the issue of how leadership-as-practice works within, but at times, as Margaret Collinson points out, works aside the leadership dimensions of power and influence.

\section{The Problem of Power in Critical and L-A-P Research [Brigid Carroll]}

Before I even start writing this piece, I find myself asking where the power lies in this very context where a scholar raises a critique about a theory and associated scholars seek to respond in kind? Here are some questions to ponder:

Does Margaret Collinson have power as the initiator, author, and researcher setting up a strong and robust engagement in a way that we expect and train for in this scholarly world? Does this collection of responders seeking to speak for a fledgling theory and respond in kind have power? 
Does the journal editor holding the space for scholarly thinking and dialogue for this journal hold the power?

Does power belong to that whole edifice of intellectual knowledge, institutions, and structures that define what counts as theory, scholarship, and ultimately knowledge of which this exchange is but one interaction?

Or is power something that all of us - scholars, journal editor, the academic community and its institutions - make and re-make between us all in interactions and routines (critique and response) such as this one that always have the choice/ possibility of cementing or moving existing practice(s)?

We thank Margaret for reminding us there is something about power with which L-A-P needs to grapple a whole lot better than it has and does. Although not often practiced in the leadership research terrain, any new theory that lays claim to criticality needs to make power central in theory and practice development. This section of the response will focus on Margaret's powerful, timely, and substantive challenge in terms of L-A-P's commitment to power. Two issues particularly invite our scrutiny: firstly, the privileging of structural asymmetry and hierarchical control as the power phenomena most alleged to be deficient and lacking in L-A-P to date and, secondly, what was less central in Margaret's critique, that being the ontological and epistemological nature of power that would be understood as emergent from the flow of temporal, situated, relational, material, and interdependent processes that constitute practice.

If we go to our own power context within scholarship evoked at the beginning of this section, then every scholar today surely feels asymmetrical power. As researchers, we seemingly enter a world where university and department heads, journal editors, and senior scholars, to name the bare minimum of the hierarchy, are already in position and the audit, assessment, funding and governing structures have dictated what is valued, prioritized, recognized, and counted. We lament the lack of time to read, support students and colleagues, write beyond the strictures and rules of publication, and be active in issues of community and society. We feel the iron cage as we discipline selves to fit it. Margaret is surely right. We feel "done to." This surely is the solidly critical discussion of power that Margaret admonishes us that L-A-P doesn't engage in. Many of the contributors in Leadership-as-Practice: Theory and Application acknowledge this inability. Barbara Simpson (2016) identifies a "naivety in failing to address issues of power" (p. 169), Caroline Ramsey (2016) recognizes that "ephemeral moments of leadership...are problematic" in terms of asymmetric power (p. 216), and Phillip Woods (2016) calls L-AP somewhat politically and ethically "neutral," given that practice can be as equally hierarchical as democratic (p. 75).

Yet, at the same time we can note that Leadership offers a space for the kind of leadership research that is not invited by other journals. We can also note that Margaret's piece is not a typical article but a 'non-traditional submission' under the category of "Leading Questions" with permission to take a different tone, intent, and structure to the typical article. In a world where journals themselves are agents of power, this journal at least carves out the possibility of a different scholarly space. It thus offers a "power to" (as opposed to "power over") for academics such as us. Such an alternative space or structure could be understood as inviting a different scholarly practice. We note Margaret is more emotive and provocative than the academic norm perhaps when she asserts that claims are "bold" ( $p$. 1), makes ironic asides "(book (sorry 'movement')" (p. 3), and uses open sarcasm ("do not despair you are now locked out of the collective") p.3). We also note that creating a composite response across a number of L-A-P theorists with varying inclinations to 'concede' or 'defend' Margaret's charges creates a less tete-à-tete energy. Nonetheless, there is plenty of normative academic prose, abstract theorizing, 
and passive constructions proving that even alternative and non-traditional spaces don't provide a complete release from well-ingrained intellectual discourse norms.

L-A-P appears stronger on accounting for the power to use (or not) such different spaces. Words connoting emergence abound in Leadership-as-Practice: Theory and Application ("unraveling" and "unfolding" (Simpson 2016, p. 159), "travel[ling]" (Ramsey 2016, p. 198) and "becoming manifest" (Kempster, Parry \& Jackson 2016, p. 245). Put simply L-A-P looks for power at the point it emerges, becomes visible, or is accomplished by both human and material agents. It sees power in the claiming of a koosh ball (Carroll 2016), the movement of conversation (Ramsey 2016), and the interplay of dialogue (Gergen \& Hersted 2016). I like Ramsey's characterization of leadership as "ephemeral" and a "moment by moment act" that produces "organizational relating" more than anything concrete (p. 216). Power exists in a ceaseless series of mostly conversational choices and openings that present fleeting possibilities to shape, move, or confirm a trajectory. We must concede there is nothing asymmetrical or structural in such power. It is the equivalent of tiny drops of emancipatory choice and not the tsunami of domination.

What I question is why criticality is more structural than agentic, domination more than emancipationoriented, pre-fixed as opposed to emergent, and linked to committed social identities (ethnicity, gender, and sexuality) as opposed to identity work (small moment-by-moment answers to who is it we think we are in a given moment and given context)? I see that avowedly critical leadership theory favors a direct confrontation with 'hard' power whilst L-A-P likes to get intimate with ambiguous spaces containing 'soft' power. In short I don't think that L-A-P is more critical than avowedly critical approaches, but I'm not entirely sure it is less critical either. It is alternatively critical perhaps. However, I see the distance between practice and more overt criticality is a longer journey than L-A-P has made: that in the dialogic, conversational, and situated moments that L-A-P opens up, institutional, structural, and systemic power is at work and L-A-P needs to be more rigorous in understanding that what is ephemeral and emergent is rarely (if at all) democratic at distance and depth (Raelin, 2011). In short, I agree there is no analytical space for practice outside power relations but there are more layers and categories of power relations than Margaret allows.

At this point I'm not thinking of the Emperor's New Clothes. I'm thinking of Little Red Riding Hood. Practice approaches look for the grandmother whilst critical approaches see the wolf. How do both learn to see that both grandmothers and wolves exist, and whilst it isn't necessarily easy to determine which you might be faced with in any one moment, critical and practice scholars of leadership can engage with both?

\section{The Practicality of Leadership-as-Practice [Brad Jackson]}

In our last contribution, Brad Jackson, Professor of Social Innovation at Griffith University, brings many of the thoughts and sentiments in the prior sections together in a personal account that speaks to the practicality of leadership-as-practice, providing a needed sense of "movement" to the field.

I want to thank Margaret Collinson for her timely and poignant provocation. This is the kind of contribution that I believe was originally anticipated when the "Leading Questions" section was first set up in the journal. Upon first reading, I will admit that I felt quite stung not so much by the arguments that were presented but more in the manner with which they were made. My primary concern initially was for Joe Raelin and the impact it would have upon him, given the personal nature of the critique. 
Upon second reading, my emotional response subsided, and I was able to focus on the important substantive issues that Margaret raised and concluded that they held considerable weight. In many respects, Margaret had scored a direct hit and I was impressed. With the third reading, I got up off the canvas and, in true Thomas the Tank Engine style said to myself: "we need to do better and we can do better." I was, therefore, pleased to be invited to come together with Joe Raelin, Brigid Carroll, Steve Kempster, and Howard Youngs in the "L-A-P spirit" to produce a response that is both individual and collective and hopefully, constructive and forward-looking.

As Prof. John Burgoyne, my doctoral supervisor encouraged me to think, L-A-P is not the way but $a$ way to think about leadership. It most definitely does not qualify as a "movement" per se but it has provided a "sense of movement," still rare in leadership studies, which has resonated positively with my governance, management, and teaching work and only more recently in my research work. It is still, as Steve Kempster notes, early days for L-A-P and we may well have gotten ahead of ourselves.

In my governance work, I have found the aspirations of the leadership-as-practice approach aligns especially well with the boards on which I have served in the social enterprise and the creative industry sectors. At the Akina Foundation, I have been struck by how many social entrepreneurs are driven not just by the desire to foster social change but also to find an alternative more collective and nonhierarchical way of working together. At Toi Whakaari, the New Zealand Drama School, we have striven to foster among our staff, students, and trustees a distinctive form of collective leadership called "koiwitanga," based on Maori Tikanga which is very similar in aspiration to L-A-P. Through these and comparable experiences working with other private and NGO organizations, I have been struck by how the university working environment has becoming increasingly anachronistic, and yet it still drives a lot of leadership scholars' thinking about leadership in organizations only because that is what they know.

This was brought graphically home to me in my management work within the university, most especially in my role as Head of School on two separate occasions in two different schools. Somewhat naively, I thought that the L-A-P approach was most in keeping with the collegial environments that academics tend to honor in the breach rather than in observance. I have never felt the asymmetrical aspects of power relations more acutely than when it was wielded by colleagues located lower down or at the same level in the hierarchy rather than by colleagues at higher levels who were generally far more humane in their approach. As Brigid Carroll has noted, while power is all-pervasive, it works in unpredictable and mysterious ways - that's what makes leadership such a compelling phenomenon to study.

Where I have found the L-A-P approach most useful is in my teaching work. Many of our students have commented on how leadership-as-practice provides a refreshing change from the myriad of leadership concepts from which they feel shut out because they cannot see either themselves or their daily work in these conceptions. In our Policy and Management Practice course, which we offer to seasoned public servants, students appreciate being able to identify, observe, and critique their policy, management, and leadership practices and are challenged to integrate these practices in order to tackle the most challenging problems they face. They also comment on a renewed sense of agency they gain by engaging with the practice approach in contrast to other courses which have a much stronger structural orientation. Sometimes we underrate the asymmetrical power that we exert over our students simply by virtue of the intractable and alienating concepts we mobilize in the interests of advancing scholarly knowledge. 
Now that I have been released from my management obligations, I am relishing the prospect of engaging in the kind of novel multi-faceted empirical work that Steve Kempster rightly observes we need to engage in through L-A-P and a whole host of other approaches. And, to pick up on Howard Youngs' argument, we need to be willing to do this in a way that transcends and not ghettoizes the leader-centered, post-heroic, and critical leadership studies paradigms that Margaret identifies.

After all, the ultimate test of any approach is the novelty, quality, and significance of the insights it yields. In order to do this we will need to be much more adventurous and expansive in the deployment of our methods. We should continue to pay heed to breakthroughs, like L-A-P, that challenge the dominant paradigm to guide those of us who are interested in better understanding the collective nature of leadership, from both appreciative and critical lenses. Sticking with the fairy tale theme reintroduced by my colleagues above, we should be willing to sample all three bowls of porridge left behind by the bears irrespective of temperature, as they each have much to commend them.

\section{Discussion [Joe Raelin]}

Having presented four perspectives of commentary on the major points of theory and practice outlined by Margaret Collinson, what remains to be attempted in this final space is an update on the state-of-thepractice of L-A-P research and application in the key contested domains.

Let's start by considering Margaret's challenge regarding the place of practice within the scholarship of leadership, whether it is all about agency, and whether its contribution is new. First, it should be acknowledged that there are practice theor[ies], suggesting less than unification around this field. The chapter by Simpson (2016) in Leadership as Practice: Theory and Application, for example, delineates a significant gulf between the meanings of practices versus practice. My own take is from the phenomenological tradition in which the intersubjective production and re-production of meaning arises through social interaction and from knowledge emanating from our social reality. As a practice theory, L-A-P submits that agency is distributed between the social world and materiality - a consistently overlooked relationship (Gherardi, 2011). Further, the relationships among subjects and between subjects and objects are recurrent, are historically situated, and consistently open to contestation.

Most practice theorists would subscribe to the view that agency and structure are mutually constituted. Alistair Mutch (2016) has suggested taking a closer look at Archer's framework of morphogenesis in which actors may choose to act in ways conditioned by structure, and in particular by institutional logics, but their actions may not need to be considered predetermined especially if they are willing to face the opportunity costs in trying alternatives. The key to change is through reflexivity, especially metareflexivity, according to Archer (2003), a process that has been widely applied in L-A-P tracts through the vehicle of dialogue. In dialogue, participants in leadership may open up new avenues of learning never considered before, not through just agreement, but foundationally through understanding and empathy. Moreover, collective agency in L-A-P occurs as an interaction between properties of participants and their relations within a group. Hence, agency can be considered a multilevel phenomenon that gets constituted and re-constituted in organizational life (Raelin, 2016; Tuominen and Lehtonen, 2017).

When it comes to the issue of the newness of L-A-P, perhaps a more critical concern is whether there may be further opportunities to explore vital questions of leadership owing to L-A-P's practice orientation. Ultimately, through practice, we can explore emergent realities from within their temporal 
unfolding or, as Harrison (2017) has put it in relation to jazz, "in the spaces between the notes." As we explore webs of activity, we take into consideration the material artifacts, the technologies, the physical arrangements, the voices, the emotions, and the rituals. And as we drill down on these practices, we acknowledge their interdependence and cross-level differences. We also become aware of what Bohm (1996) referred to as the body's "proprioceptive" state in which without detaching body from thought, we learn to appreciate embodied and kinaesthetic processes as a source of tacit knowledge and reflective consciousness (Gunnlaugson, 2014; Rigg, 2017).

By considering leadership in L-A-P as turning points that re-orient the flow of practice towards new meanings and direction (Simpson, 2016), there is the risk of omitting acknowledgement of its ideological nature. Such an omission challenges its presumed value-neutrality and subjects it to the post-humanist critique questioning any authentic engagement by autonomous subjects (Bryant \& Wolfram Cox, 2014; Woods, 2016). As Margaret attests, there are too many instances of unjust process dynamics that submit organizational members to the forces of objectification. We need to actualize a practice ontology, rather than merely advocate for it, that truly privileges the value of social interactions that, in turn, rely upon reflective emancipatory processes in which taken-for-granted assumptions and meanings become subject to scrutiny (Raelin, 2011).

We close with an appreciation to our editor, Dennis Tourish, and again to Margaret Collinson for raising such important issues as we wrestle with the institution of leadership in the contemporary world. We hope we have demonstrated that leadership can be a collaborative practice based on communal constitution and process.

\section{References}

Alvesson M and Spicer A (2014) Critical perspectives on leadership. In Day, D V (ed) The Oxford Handbook of Leadership and Organizations. Oxford: Oxford University Press, pp. 40-56.

Archer M S (1995) Realist Social Theory: The Morphogenetic Approach. Cambridge: Cambridge University Press.

Archer M S (2003) Structure, Agency, and the Internal Conversation. Cambridge: Cambridge University Press.

Bohm D (1996). On Dialogue. London and New York: Routledge.

Bryant M and Wolfram Cox J (2014). Beyond authenticity? Humanism, posthumanism, and the new OD. British Journal of Management 25: 706-723.

Carroll B, Levy L and Richmond D (2008) Leadership as practice: Challenging the competency paradigm. Leadership 4(4): 363-380.

Collinson D (2014) Dichotomies, dialectics and dilemmas: New directions for critical leadership studies? Leadership 10(1): 36-55.

Collinson M (2017) Leading questions: What's new about Leadership-as-Practice?" Leadership. Available at: http://journals.sagepub.com/doi/abs/10.1177/1742715017726879 (accessed 15 October 2017). 
Crevani L (2017) Is there leadership in a fluid world? Exploring the ongoing production of direction in organizing. Leadership. Available at: http://journals.sagepub.com/doi/abs/10.1177/1742715015616667 (accessed 15 November 2017).

Drath W H, McCauley, C D, Palus, C L, Van Velsor E, O'Connor P M G and McGuire J B (2008) Direction, alignment, commitment: Toward a more integrative ontology of leadership. Leadership Quarterly 19(6): 635-653.

Gherardi S (2011) Organizational learning: The sociology of practice. In Easterby-Smith $M$ and Lyles M A (eds) The Blackwell Handbook of Organizational Learning and Knowledge Management. Chichester, UK: Wiley, pp. 43-65.

Gronn P (2011) Hybrid configurations of leadership. In Bryman A, Collinson D, Grint K, Jackson B and UhlBien M (eds.) The Sage Handbook of Leadership. London: Sage Publications, pp. 437-454.

Gunnlaugson O (2014) Bohmian dialogue: A critical retrospective of Bohm's approach to dialogue as a practice of collective communication. Journal of Dialogue Studies 2(1): 25-34.

Harrison R T (2017) Leadership, leadership development and all that jazz. Leadership 13(1): 81-99.

Hunt J G (1999), Transformational/charismatic leadership's transformation of the field: An historical essay. Leadership Quarterly 10(2): 129-144.

Kelly S (2014) Towards a negative ontology of leadership. Human Relations 67(8): 905-922.

Kemmis S, Wilkinson J, Edwards-Groves C, Hardy I, Grootenboer P and Bristol L (2014) Changing Practices, Changing Education. Singapore: Springer.

Kempster S and Gregory S H (2017) 'Should I stay or should I go?' Exploring leadership-as-practice in the middle management role. Leadership 13(4): 496-515.

Mutch A (2017) Margaret Archer and a morphogenetic take on strategy. Critical Perspectives on Accounting. Available at: http://www.sciencedirect.com/science/article/pii/S104523541730028X (accessed 10 October 2017).

Raelin J A (2011) From leadership-as-practice to leaderful practice. Leadership 7: 195-211.

Raelin J A (2016) Imagine there are no leaders: Reframing leadership as collaborative agency. Leadership 12(2): 131-158.

Raelin J A (ed) (2016). Leadership-as-Practice: Theory and Application. New York: Routledge, and the following cited chapters:

Carroll B J Leadership as identity: A practice-based exploration, pp. 91-109, Chap. 5. Gergen K J and Hersted L Developing leadership as dialogic practice, pp. 178-197, Chap. 9. Kempster S, Parry K and Jackson B Methodologies to discover and challenge leadership-as-practice, pp. 242-261, Chap. 12.

Ramsey C Conversational travel and the identification of leadership phenomena, 198-220, Chap. 10. 
Simpson B Where's the agency in leadership-as-practice? pp. 159-177, Chap. 8.

Woods P A Democratic roots: Feeding the multiple dimensions of leadership-as-practice, pp. 70-88, Chap. 4.

Reichers A E and Schneider B (1990) Climate and cultures: An evolution of constructs. In Schneider B (ed) Organizational Climate and Culture. San Francisco: Jossey-Bass, pp. 5-39.

Rigg C (2017) Somatic learning: Bringing the body into critical reflection. Management Learning, Available at: http://journals.sagepub.com/doi/abs/10.1177/1350507617729973 (accessed 10 November 2017).

Schatzki T R, Cetina K K and Savigny E V (eds) (2001) The Practice Turn in Contemporary Theory. London: Routledge.

Thomson P (2005) Bringing Bourdieu to policy sociology: Codification, misrecognition and exchange value in the UK context. Journal of Education Policy 20(6): 741-758.

Thrupp M and Willmott R (2003) Education Management in Managerialist Times: Beyond the Textual Apologists. Maidenhead: Open University Press.

Tuominen T M and Lehtonen M H (2017) The emergence of transformative agency in professional work. Organization Studies. Available at: http://journals.sagepub.com/doi/full/10.1177/0170840617717093 (accessed 15 October 2017).

Wilkinson J and Kemmis S (2015) Practice theory: Viewing leadership as leading. Educational Philosophy and Theory 47(4): 342-358.

Youngs $\mathrm{H}$ (2009) (Un)Critical times? Situating distributed leadership in the field. Journal of Educational Administration and History, 41(4): 377-389.

Youngs H (2017a) (Re)positioning the distributed 'turn' in leadership. In Lakomski G, Eacott S and Evers C W (eds.) Questioning Leadership: New Directions for Educational Organisations. London: Routledge, pp. 139-150.

Youngs H (2017b) A critical exploration of collaborative and distributed leadership in higher education: Developing an alternative ontology through leadership-as-practice. Journal of Higher Education Policy and Management 39(2), 140-154. 